\title{
SISTEM INFORMASI PEMETAAN POTENSI SUMBERDAYA ALAM
}

\author{
Dedi Irawan", Adi Gustian' \\ ${ }^{1,2}$ Program Studi Sistem Informasi, Universitas Bina Darma \\ Jalan Jenderal Ahmad Yani No.3 Palembang \\ Sur-el : dedi.irawan@binadarma.ac.id', adigustian@gmail.com²
}

\begin{abstract}
Penukal Abab Lematang Ilir Regency is one of the regencies in southern Sumatra that has abundant natural resources such as oil, natural gas and coal which reach $76.12 \%$ per year of total revenue in various sectors. The following table is the sub-district natural resources in the Penukal Abab Lematang Ilir Regency, As a newly established district, the new autonomous region, Penukal Abab Lematang Ilir still has many shortcomings, both in human resources, community governance and technology as a means of supporting work activities in the district This, including one of the technologies for discovering natural resources in the earth, Penukal Abab Lematang Ilir Regency as a government asset, is currently still being done manually both in terms of monitoring and storing data, making it less efficient in reading accuracy. As a solution, a natural resource potential mapping information system was created. Penukal Abab Lematang Ilir District used the action research method and ArcGis software.
\end{abstract}

Keywords: Natural resources, Efficient, Action Research, ArcGis

\begin{abstract}
Abstrak: Kabupaten Penukal Abab Lematang Ilir adalah salah satu kabupaten di Sumatra bagian selatan yang memiliki sumber daya alam yang melimpah seperti minyak, gas alam, dan batubara yang mencapai 76,12\% per tahun dari total pendapatan di berbagai sektor. Tabel berikut adalah sumber daya alam kecamatan di Kabupaten Penukal Abab Lematang Ilir, Sebagai kabupaten yang baru didirikan, daerah otonom baru, Penukal Abab Lematang Ilir masih memiliki banyak kekurangan, baik dalam sumber daya manusia, pemerintahan masyarakat dan teknologi sebagai sarana pendukung kegiatan kerja di kabupaten tersebut, termasuk salah satu teknologi untuk menemukan alam sumber daya yang ada di bumi Kabupaten Penukal Abab Lematang Ilir sebagai aset pemerintah, yang saat ini prosesnya masih dilakukan secara manual baik dari sisi pemantauan maupun penyimpanan data, sehingga kurang efisien dalam akurasi membaca. Sebagai solusi, maka dibuatlah sistem informasi pemetaan potensi sumber daya alam Kabupaten Penukal Abab Lematang Ilir menggunakan metode penelitian tindakan dan perangkat lunak ArcGis
\end{abstract}

Kata kunci: Sumber daya alam, Efisien, Penelitian Tindakan, ArcGis

\section{PENDAHULUAN}

Sistem Informasi Geografis (SIG) ialah sistem informasi yang digunakan untuk memasukkan, menyimpan, memanggil kembali, mengolah, menganalisis dan menghasilkan data referensi geografis atau data geospatial, tujuannya mendukung pengambilan keputusan dalam perencanaan dan pengelolaan penggunaan lahan, sumber daya alam dan pelayanan umum lainnya.[1] SIG merupakan sistem informasi berbasis komputer yang digunakan untuk mengolah dan menyimpan data atau informasi geografis.[2] Seperti informasi yang berisi mengenai lokasi suatu daerah dan informasi mengenai sumber daya alam yang terkandung pada daerah tersebut. Dengan adanya sistem informasi geografis dapat mempercepat dan mempermudah dalam mendapatkan informasi tersebut.[3]

Wilayah merupakan sebuah entitas yang multitafsir. Wilayah dapat berupa sebuah area 
yang berada dalam kesatuan administratif atau tataran politik tertentu (misalnya desa, kecamatan, propinsi, dan negara) atau sebuah area memiliki kesamaan ciri alami tertentu (topografi, ekosistem, iklim dan lainnya).[4] Sumber daya alam Indonesia yang sangat melimpah tersebut sebagian besar terletak di daerah terpencil seperti di pedesaan. Sumber daya alam di pedesaan seperti hamparan hutan sangat luas, sumber air seperti sungai, danau, lahan pertanian dan lainnya. [5]

Kabupaten Penukal Abab Lematang Ilir adalah salah satu Kabupaten di Provinsi Sumatera Selatan. Kabupaten Penukal Abab Lematang Ilir terbentuk dari hasil pemekaran Kabupaten Muara Enim Secara yuridis pembentukan Kabupaten PALI disahkan berdasarkan Undang-Undang R I No. 7 Tahun 2013 tanggal 11 Januari 2013, Luas wilayah Kabupaten Penukal Abab Lematang Ilir 1.840 $\mathrm{Km}^{2}$ atau 2,11\% dari Total Provinsi Sumatera Selatan dengan Jumlah Penduduk 171,084 Jiwa pada tahun 2012 yang terdiri dari 5 Kecamatan, 65 desa, 6 kelurahan, 213 dusun, 47 RW dan 148 RT. Untuk Daerah Aliran Sungai (DAS) yang ada di Kabupaten Penukal Abab Lematang Ilir hanya ada dua yaitu Sungai Musi dan Sungai Lematang.[6]

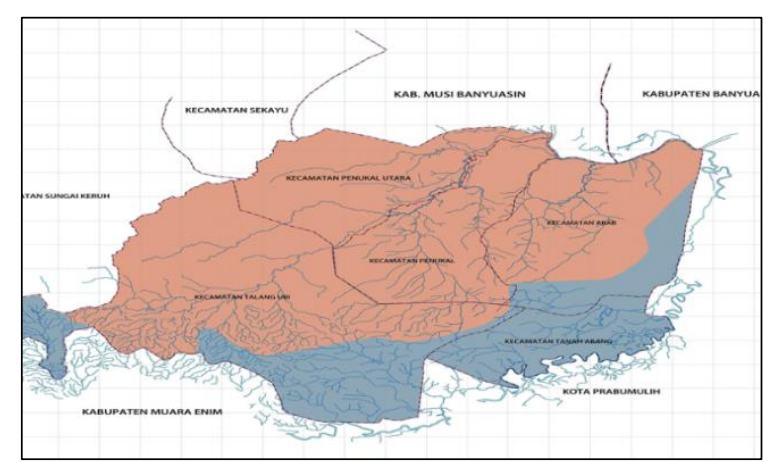

Gambar 1. Peta Wilayah Kabupaten PALI
Kabupaten PALI merupakan salah satu kabupaten yang memiliki sumberdaya alam yang cukup melimpah seperti Minyak, Gas Bumi dan Batu Bara yang mencapai $76.12 \%$ pertahun dari jumlah pendapatan di berbagai sektor. Tabel 1 menunjukkan sumber daya alam perkecamatan di Kabupaten PALI.

Tabel 1. SDA kecamatan di Kab. PALI. [7]

\begin{tabular}{|c|c|c|c|c|}
\hline \multirow[t]{3}{*}{$\begin{array}{c}\text { Nama } \\
\text { Kecamata } \\
n\end{array}$} & \multirow{3}{*}{$\begin{array}{c}\text { Jumla } \\
\text { h } \\
\text { Kelur } \\
\text { ahan } \\
\text { atau } \\
\text { Desa } \\
\end{array}$} & \multirow{2}{*}{\multicolumn{3}{|c|}{$\begin{array}{c}\text { Jumlah penghasilan (SDA) } \\
\text { perkecamatan di Kabupaten PALI } \\
\text { Periode 2017-2018 } \\
\text { Sumber Daya Alam }\end{array}$}} \\
\hline & & & & \\
\hline & & Minyak & Gas Bumi & Batubara \\
\hline Abab & 8 & 20.0579 & 0.8318 & 0.909102 \\
\hline Penukal & 13 & 29.2701 & 1.6636 & 0.454 .551 \\
\hline $\begin{array}{c}\text { Penukal } \\
\text { Utara }\end{array}$ & 13 & 30.4215 & 1.6636 & 0.6818265 \\
\hline Talang Ubi & 20 & 84.132134 & 4.9908 & 1.363653 \\
\hline $\begin{array}{l}\text { Tanah } \\
\text { Abang }\end{array}$ & 18 & 88.515067 & 3.3272 & 0.6818265 \\
\hline Jumlah & 72 & $\begin{array}{l}252.397,03 \\
\text { MSTB }\end{array}$ & $\begin{array}{l}12.477,07 \\
\text { BSCF }\end{array}$ & $\begin{array}{l}3.4091325 \\
\text { Ton }\end{array}$ \\
\hline
\end{tabular}

Sebagai kabupaten yang baru terbentuk, daerah otonom baru (DOB), PALI masih banyak kekurangan, baik dalam sumber daya manusia, pelayanan masyarakat maupun teknologi sebagai sarana penunjang aktifitas pekerjaan kabupaten tersebut, termasuk salah satunya teknologi untuk mengetahui potensi sumber daya alam yang ada di bumi Kabupaten PALI sebagai aset pemerintahan, dimana pada saat ini proses tersebut masih dilakukan secara manual baik dari sisi pemetaan maupun penyimpanan data, sehingga kurang begitu efisien dalam ketepatan mengetahui batasan suatu daerah yang dinilai memiliki kandungan sumber daya alam. Dalam mengatasi permasalahan dilakukan perancangan dan pembangunan sebuah Sistem Informasi Pemetaan untuk Mengetahui Potensi Sumber Daya Alam di Kab. PALI. 


\section{METODOLOGI PENELITIAN}

Dalam penelitian ini peneliti menggunakan metode penelitian Action research yang terdiri dari 5 tahapan yang merupakan siklus [8], yaitu: a. Melakukan diagnosa (diagnosing), Melakukan identifikasi masalah-masalah pokok yang ada guna menjadi dasar pembuatan sebuah sistem sesuai dengan kebutuhan user administrator, ditempuh dengan cara mengadakan wawancara mendalam kepada user administrator yang terkait langsung maupun yang tidak terkait langsung dengan penggunaan sistem informasi geografis yang akan dibangun.

b. Membuat rencana tindakan (action planning), Peneliti dan partisipan bersama-sama memahami pokok masalah yang ada kemudian dilanjutkan dengan menyusun rencana tindakan yang tepat untuk menyelesaikan masalah yang ada, pada tahap ini pembuatan sistem informasi geografis memasuki tahapan desain sistem informasi geografi. Dengan memper hatik-

an kebutuhan user administrator terhadap sistem informasi geografis penelitian bersama partisipan memulai membuat sketsa awal dan menentukan isi yang akan ditampilkan nantinya.

c. Melakukan tindakan (action taking), Peneliti dan partisipan bersama-sama mengimplementasikan rencana tindakan dengan harapan dapat menyelesaikan masalah. Selanjutnya setelah model dibuat berdasarkan sketsa dan menyesuaikan isi yang akan ditampilkan berdasarkan kebutuhan user administrator dilanjutkan dengan mengadakan ujicoba awal.

d. Melakukan evaluasi (evaluating), Setelah masa implementasi (action taking) dianggap cukup kemudian peneliti bersama partisipan melaksanakan evaluasi hasil dari implementasi tadi, dalam tahap ini dilihat bagaimana penerimaan user administrator yang ditandai dengan berbagai aktivitasaktivitas.

e. Pembelajaran (learning), Tahap ini merupakan bagian akhir siklus yang telah dilalui dengan melaksanakan review tahappertahap yang telah berakhir kemudian penelitian ini dapat berakhir.[8]

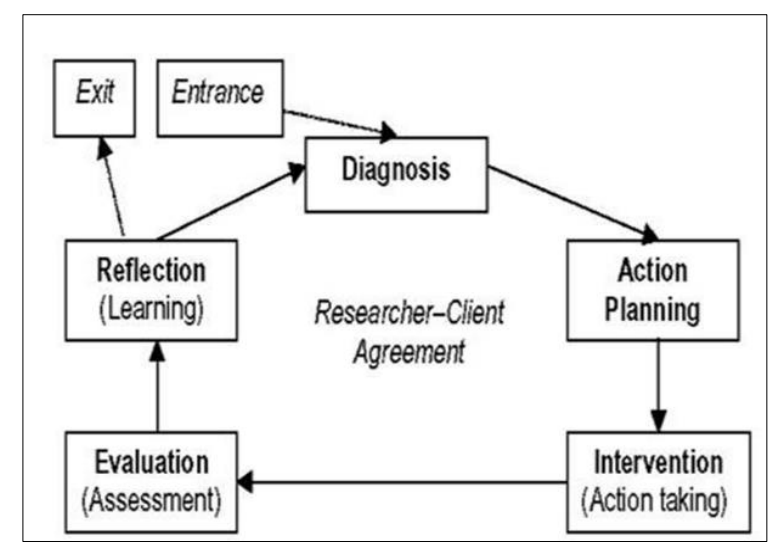

Gambar 2. Metodologi Action research

\section{HASIL DAN PEMBAHASAN}

\subsection{Pengujian Sistem,}

Agar hasil implementasi benar-benar memenuhi kebutuhan maka dilakukan pengujian terhadap sistem. Pengujian dilakukan dengan menguploadkan hasil pemetaan GIS kedalam account GIS ESRI. Serta mencoba beberapa aktivitas seperti melihat batas wilayah Kecamatan, potensi Sumberdaya alam. Dengan 
tahapan membuat account sebagai login administrator nantinya untuk melihat informasi potensi sumberdaya alam yang terdapat di Kabupaten PALI perkecamatan seperti di Kec. Penukal, Kec. Penukal Utara, Kec. Abab, Kec. Talang Ubi, Kec. Tanah Abang. Setelah account berhasil dibuat maka proses berikutnya mengupload peta ke dalam website ArcGIS Online.

\subsubsection{Tampilan halaman website ArcGIS}

Tahap pertama peneliti mengunjungi website ArcGIS yaitu www.arcgis.com untuk melakukan proses upload hasil pemetaan yang telah dibuat berdasarkan data yang telah didapatkan sebelumnya dari dinas terkait.

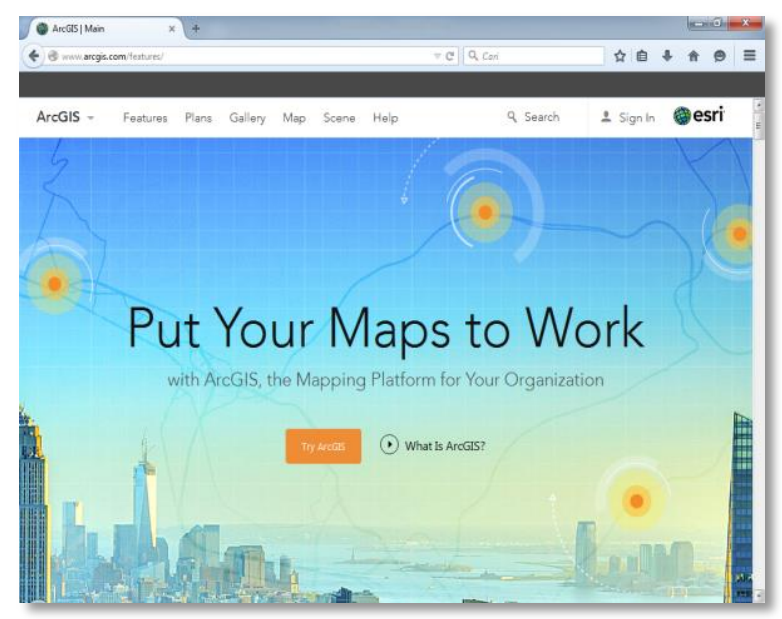

Gambar 3. Halaman website ArcGIS

\subsubsection{Tampilan antarmuka login ESRI}

Tahap ini peneliti melakukan login dengan username dan password yang telah terdaftar sebelumnya yaitu menggunakan username tamiutami password tamiutami**** Tampilan antar muka Login ESRI dapat dilihat pada gambar 4 .

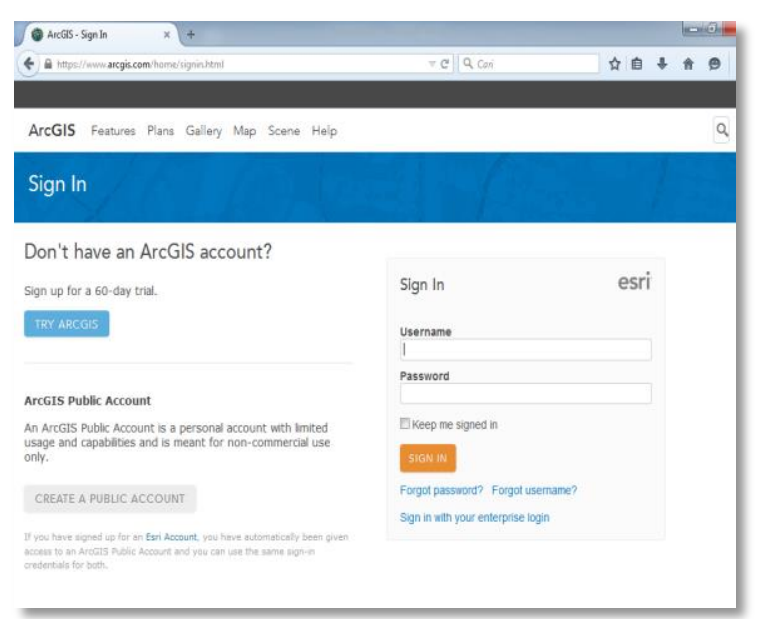

Gambar 4. Antar muka login ESRI

\subsubsection{Halaman Utama ArcGIS ESRI}

Tampilan utama ketika user sudah melakuan login artinya user sudah berada pada user interface pribadinya dapat dilihat pada gambar 5.



Gambar 5. Halaman utama login

\subsubsection{Hasil upload peta sumber daya alam.}

Pada tahap ini peneliti telah melakukan proses upload hasil pemetaan sumber daya alam perkecamatan sekabupaten PALI. Hasil Upload Pemetaan SDA terlihat seperti pada gambar 6. 




Gambar 6. Hasil upload pemetaan SDA

\subsubsection{Proses request hasil upload peta}

Pada tahap ini peneliti melakukan request terhadap hasil upload peta sumber daya alam yang ada pada menu my content.



Gambar 7. Request hasil upload peta SDA

\subsubsection{Hasil Upload Peta perkecamatan}

Setelah melakukan proses upload beberapa peta kecamatan maka didapat hasil menjadi kabupaten PALI dapat dilihat pada gambar 8 .



Gambar 8. Hasil Upload Peta Perkecamatan

\subsubsection{Potensi SDA di Kec. Abab}

Dari hasil pemetaan maka dapat dilihat potensi sumber daya alam yang ada di kecamatan Abab secara sistematis, seperti terlihat pada gambar 9 .

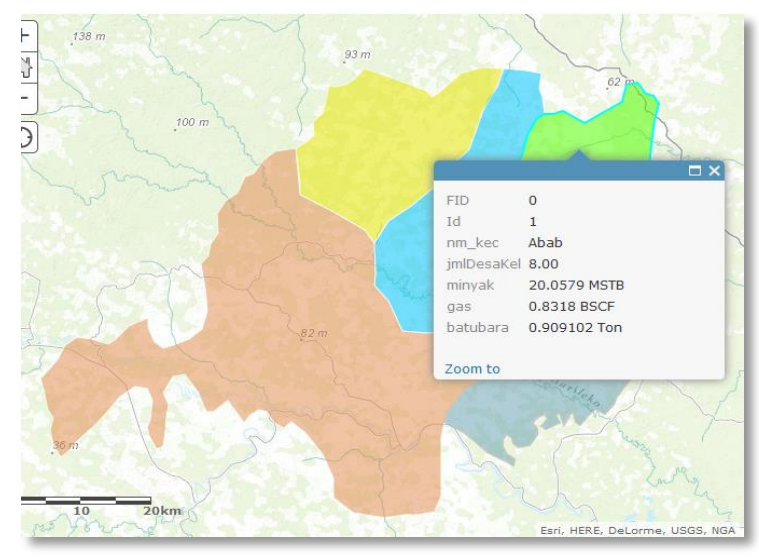

Gambar 9. Potensi SDA Kec. Abab

\subsubsection{Potensi SDA di Kec. Penukal}

Gambar 10 menunjukkan hasil pemetaan potensi sumber daya alam yang ada di Kecamatan Penukal.



Gambar 10. Potensi SDA Kec. Penukal

\subsubsection{Potensi SDA di Kec. Penukal Utara}

Pemetaan potensi sumber daya alam yang ada di Kecamatan Penukal Utara secara sistematis dapat dilihat pada gambar 111. 




Gambar 11. Potensi SDA Kec. Penukal Utara

\subsubsection{Potensi SDA di Kec. Talang Ubi}

Ppotensi sumber daya alam yang ada di Kecamatan Talang Ubi, secara sistematis dapat dipetakan seperti yang terlihat pada gambar 12 .

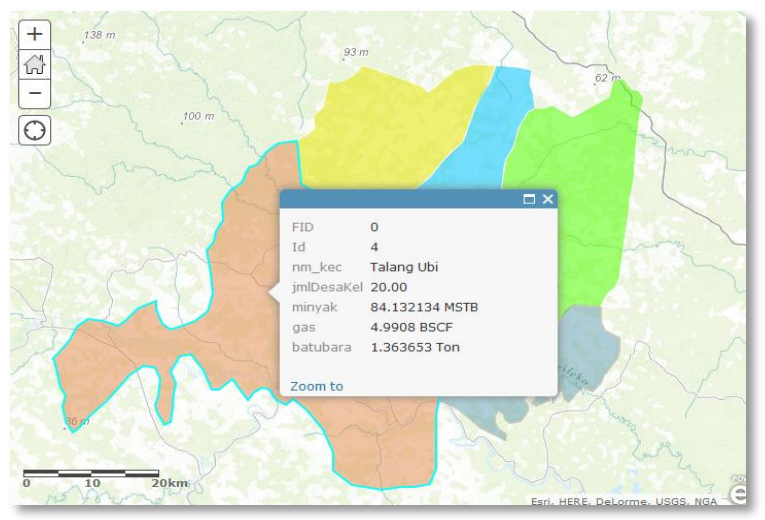

Gambar 12. Potensi SDA Kec. Talang Ubi

\subsubsection{Potensi SDA di Kec. Tanah Abang}

Pemetaan potensi sumber daya alam yang ada di Kecamatan Tanah Abang dapat dilihat pada gambar 13.

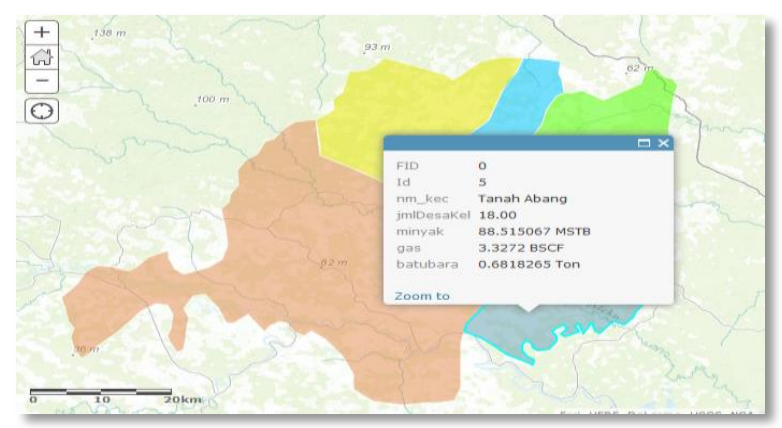

Gambar 13. Potensi SDA Kec. Tanah Abang

\subsection{Melakukan evaluasi (evaluating)}

Evaluasi dapat dilakukan untuk mengetahui bagaimana penerimaam pengguna terhadap sistem informasi yang dibangun. Kegiatan Implementasi dapat dilakukan jika sistem informasi yang telah dibangun siap digunakan. Sebelum digunakan sistem harus dihosting terlebih dahulu agar dapat di akses secara online oleh pengguna. Tahap evaluasi belum dilaksanakan

\subsection{Pembelajaran (learning)}

Tahap ini merupakan bagian akhir siklus yang telah dilalui dengan melaksanakan review tahap-pertahap yang telah berakhir kemudian penelitian ini dapat berakhir. Seluruh kriteria dalam prinsip pembelajaran harus dipelajari, perubahan dalam situasi organisasi dievaluasi oleh peneliti dan dikomunikasikan kepada klien, Peneliti dan klien merefleksikan terhadap hasil proyek, yang nampak akan dilaporkan secara lengkap dan hasilnya secara eksplisit dipertimbangkan dalam hal implikasinya terhadap penerapan Canonical Action Reaserch $(C A R)$. Untuk hal tertentu, hasilnya dipertimbangkan dalam hal implikasinya untuk tindakan berikutnya dalam situasi organisasi lebih-lebih kesulitan yang dapat dikaitkan dengan pengimplementasian perubahan proses.

\section{KESIMPULAN}

Berdasarkan hasil penelitian dan uji coba yang telah dilakukan, maka peneliti menyimpulkan, bahwa dengan adanya sistem informasi pemetaan potensi sumber daya alam 
ini dapat membantu meringankan pekerjaan pihak Dinas Pertambangan, Energi dan Lingkungan Hidup Kabupaten Pali, dimana proses pemetaan tersebut dapat dilakukan secara sistematis, cepat dan akurat sehingga aktivitas pekerjaan yang dilakukan dapat lebih efektif dan efisien.

\section{DAFTAR PUSTAKA}

[1] A. Wijaya and O. Ayundha, "Sistem Informasi Geografis Pemetaan Kantor Dinas Pemerintah Kota Palembang menggunakan ArcGIS," Semin. Nas. Teknol. Inf. Komun. Terap. 2014, no. November, pp. 129-134, 2014.

[2] K. Mangkusubroto, Modul Pelatihan ArcGIS Tingkat Dasar. Banda Aceh, 2007.

[3] A. A. Sasoeng, S. R. Sentinuwo, and Y. D. Y. Rindengan, "Rancang Bangun Sistem Informasi Geografis Potensi Sumber Daya Alam Di Kabupaten Talaud Berbasis Web," J. Tek. Inform., vol. 13, no. 1, pp. 1-8, 2018.

[4] S. E. a; J. F. Dewi, Sistem informasi geografis untuk Pengelolaan Bentang Lahan Berbasis Sumber Daya Alam. Bogor: ICRAF South East Asia, 2009.

[5] Tambunan Joel, "Indonesia kaya akan sumber daya alam namun miskin sumber daya manusia," 2015. [Online]. Available:

http://fwatcher.fwi.or.id/indonesia-kayaakan-sumber-daya-alam-namun-miskinsumber-daya-manusia/.

[6] S. Efendi, "Dok BPS BAB 1 Kab," 2014.

[7] B. Raka, "Dok. BPS BAB II Kab. Pali hasil Pokja," 2016. [Online]. Available: http://ppsp.nawasis.info/dokumen/perenc anaan/sanitasi/pokja/bp/kab.penukalababl ematangilir/Dok. BPS BAB II Kab. Pali hasil Pokja.doc.

[8] K. N. Davison, R. M., Martinsons, M. G., Principles of Canonical Action Research. 2004. 